\title{
Un Derecho procesal para todos los tiempos...desde Carlos V al tercer milenio
}

Mario Masciotra

Convocado por la Asociación Internacional de Derecho Procesal, que preside el Prof. Marcel Storme, se desarrolló durante los días 25 a 28 de abril del corriente año en la ciudad de Gante (Bélgica) el Coloquio Internacional de Derecho Procesal, con el título de referencia.

Participaron ciento treinta procesalistas, entre los cuales podemos mencionar a P. Gilles, B. Hess, P. Gottwald (Alemania), A. M. Morello, G. L. Sosa, A. Ledesma, J. C. Hitters, A. Valcarce, (Argentina), N. Andrews (Australia), Barbosa Moreira, A. De Pellegrini (Brasil), V. Fairen Guillén, I. Díez Picazo (España), G. Bolard (Francia), Yessiou-Faltsi (Grecia), N. Andrews, Peysner (Inglaterra), F. Carpi, I. A. Andolina, M.Taruffo, G. Tarzia (Italia), S. Shetreeet (Israel), Weidong Ji (Japón), Gomez Lara (México), A. Quiroga León (Perú), Ferreira Da Silva (Portugal), W. De Vos (Sudáfrica), Vescovi, J.Greif (Uruguay), P. Carrington, G. Hazard (USA), entre otros.

Habiendo sido designada la ciudad de Gante como sede del coloquio por celebrarse en ella el quinto centenario del nacimiento de Carlos V resultó inexorable referirse a su pensamiento y accionar político.

$\mathrm{Y}$ en ese sentido, se destacó que quien fuera rey por nacimiento y emperador por elección, no tenía buen concepto de los juristas y se opuso terminantemente a que los abogados se trasladen a América para no producir anarquía ni conflictos estériles. 
El descrédito de la justicia en esa época era alarmante, los abogados percibían sus honorarios conforme a la extensión de las presentaciones que redactaban, lo que provocaba densos desarrollos e innecesarios planteos, escritos con mucha cantidad de fojas (se relata que escribían cuatro palabras por renglón y catorce renglones en cada página).

Por su parte, la morosidad de los jueces era tan manifiesta que los litigantes debían perseguir a los funcionarios para que dictaran pronunciamiento (pudo haber sido el origen de los «lobbistas» judiciales).

No obstante la opinión que le merecía a Carlos $\mathrm{V}$ la actuación de abogados y jueces, tenía la convicción de la importancia del Derecho Procesal -aun cuando éste carecía de autonomía científica- y de la necesidad imperiosa de mejorar la administración de la justicia.

En esa inteligencia y con ese espíritu, no sólo ordenó compilar las normas consuetudinarias de carácter procesal que imperaban entonces, que fue el primer intento de codificación procesal, sino que intentó reformas sustanciales tendientes a disminuir el costo y el tiempo de los litigios, ya que los procedimientos eran costosos y los juicios muy lentos.

Producto de su incansable labor, décadas después durante la gestión de Fernando II -emperador germánico- se publicó el primer Manual de Derecho Procesal Civil que data de 1626 de Joost de Damhouder Practycke Civile, cuyo ejemplar fue obsequiado a los concurrentes al Coloquio.

Cabe destacar que el citado autor, a quien podemos calificar como el primer tratadista de Derecho Procesal ante la indiscriminada iniciación de pleitos que inundaban los tribunales de la época y para paliar dicha situación anunció tres remedios: 1) los litigantes debían privilegiar el espíritu solidario en sus relaciones contractuales; 2) los abogados, debían contener sus ansias de ganar dinero; y, 3) los jueces debían, a su vez, tener más fervor, una mayor dedicación y asumir un rol activo en el proceso judicial.

Como puede percibirse claramente, los problemas judiciales que aquejaban a la sociedad flamenca de principios del siglo XVII son muy similares a los que padecemos actualmente.

Las soluciones que se diseñaron en el pasado y las que deben vertebrarse casi cuatro siglos después, más allá de los avances tecnológicos que nos depara esta última década, encuentran su fundamento en las cualidades humanas, los valores éticos, el espíritu de sacrificio y criterio de responsabilidad que debe primar entre todos los que esta- 
mos involucrados en el quehacer judicial, abogados, jueces, docentes, estudiantes, periodistas, legisladores, gobernantes, en fin, los ciudadanos todos, sin exclusión alguna.

Privilegiando estos valores y teniendo como premisa liminar que la eficacia de la jurisdicción es la base del estado de derecho se solidificará la credibilidad de la justicia ante la comunidad.

La solidez intelectual de los participantes, su elevado número y la representatividad de los mismos, pues provenían de países de los cinco continentes, permitió recepcionar información actualizada acerca de la situación en que se encuentran las normativas procesales y las administraciones judiciales de estados tan lejanos como disímiles.

Estas son algunas de las impresiones recogidas y de los conceptos vertidos en el importante evento académico:

\section{Área asiática:}

En China, a partir de 1993 se han puesto en ejecución importantes reformas procesales, tales como:

- Activo trabajo pre-judicial para evitar la contienda.

- Otorgar mayor importancia a la mediación, aunque continúa siendo facultativa del juez.

- Estadio procesal previo al juicio oral tendiente a depurar el procedimiento.

- La prueba es a cargo de las partes.

- Autorizar a los tribunales a aplicar sanciones en caso de abuso procesal (Ji Wiedong).

No obstante, las sustanciales innovaciones encaradas, es escasa e insuficiente la inmediación de los jueces.

En Japón la discrecionalidad judicial y la incertidumbre tanto legislativa como la emanada de los jueces ha provocado una gran antipatía por los litigios, generando una creciente canalización de los conflictos a través de los sistemas alternativos de solución de conflictos ADR (negociación, conciliación, mediación y arbitraje). 
Japón carece de tradición jurídica, el número de juristas es reducido y es uno de los pocos países del mundo donde escasean los abogados (Takeshi Kojima).

\section{Area Africana:}

La Constitución de Sudáfrica de 1985 establece en forma expresa que los ciudadanos deben gozar de un proceso justo, del derecho a ser oído, de un juez independiente y derecho a acceso a la justicia.

Influenciado por la prédica doctrinaria de Mauro Cappelletti en 1985 se implementó un procedimiento abreviado, para juicios de menor cuantía, que presenta las siguientes características:

- No hay representación legal ni asistencia letrada.

- El funcionario interviniente, que actúa ad-honoren pues forma parte de la comunidad, tiene un rol muy activo.

- El procedimiento es inquisitorio, no hay investigación contradictoria, y se trata de un sistema consuetudinario.

- El funcionario -comisario- posee una vasta discrecionalidad pues goza de amplísima libertad para flexibilizar el procedimiento y para ordenar y recepcionar la prueba que considere más conveniente.

- No hay recurso sino un reexamen por parte del Tribunal Superior (Wouter De Vos).

\section{Área europea oriental:}

En el mundo occidental existe una tendencia hacia un mayor activismo judicial, mientras que en Europa del este, es a la inversa, se tiende a restringir las facultades del juez. Tal situación tiene motivaciones ideológicas, por cuanto en la época socialista y durante un dilatado lapso se impuso un rígido y acendrado intervencionismo estatal.-

A partir de la democratización de los regímenes socialistas comienza una transformación en la estructura de los procedimientos judiciales, se evoluciona hacia un concepto privatístico fundado en motivaciones ideológicas y se desarrolla el principio de la autonomía de la voluntad; como consecuencia de ello, en los países del este los jueces no están facultados para decretar medidas de mejor proveer (Paul Oberhamer).

Durante la última década Croacia convive tiempos de guerra y de paz, a partir del abandono del sistema socialista, no se ha podido es- 
tructurar ni solidificar un sistema democrático. Actualmente vive una época de transición, se cambió un sistema político, se creó un estado independiente y se ganó una guerra.

Con anterioridad, el Poder Judicial no era independiente, era un acápite del poder ejecutivo, el socialismo no admitía la división de poderes.

La Constitución de 1990 reconoció la división de poderes, la inamovilidad de los jueces, la independencia del poder judicial. A partir de la democratización de las estructuras políticas, los jueces se politizaron y se violaron frecuentemente las garantías constitucionales. Cuando terminó la guerra en 1996 se abolieron los tribunales marciales. Durante la confrontación bélica se produjo el exilio de los jueces.

Actualmente existe un Consejo Judicial del Estado, cuyos miembros los designa el Parlamento encargado de la selección y designación de los magistrados. El 25\% de los jueces tienen menos de 35 ańos, unos son amanuenses del gobierno, otros son inexpertos e incapaces y existe una manifiesta morosidad en la labor judicial. Conclusión, el poder judicial no está ahora mejor que en la época socialista.(Alan Uzelac).

Área europea occidental:

En Suecia rige un sólo código de procedimientos civil y penal. Ello explica que el rol del juez sea sumamente activo que intervenga libremente; el proceso está más próximo a la gente. Las partes se presentan sin abogados, de ahí que el juez no puede quedarse con los brazos cruzados en un rol pasivo.(Sakari Laukkanen).

En Portugal a mediados de 1998, se aplicó un proceso monitorio "puro" para el cobro de pequeños importes. Las empresas envían su reclamo mediante disquette que lo recepciona una Secretaría, en la cual se sustancia las actuaciones. No hay representación legal obligatoria. (C. M. Ferreira Dasilva).

Los juicios complejos, es decir, procedimientos para asuntos difíciles, de un importante caudal patrimonial como el caso de las class action o acciones colectivas, no se conocen en Europa, se resuelven a través de otros mecanismos.

Las acciones colectivas no se compadecen con el purismo jurídico que rige en Alemania donde se admiten sólo los juicios individuales. Admitir aquéllas afirmó Paul Oberhammer generará numerosos inconvenientes. 
Los procesos complejos se pueden dar en juicios donde estén involucrados importantes empresas y los montos reclamados sean muy elevados.

La realidad tribunalicia refleja que los importes demandados y que son materia de condena en EE.UU. superan diez veces más los montos que se cuestionan en Europa.

En EE.UU. los letrados no concurren a los tribunales, mientras que en Alemania y Austria los abogados se forman profesionalmente y profundizan sus conocimientos litigando. El país germano se ha convertido en el más litigioso del mundo, a pesar de que el $80 \%$ de los contratos internacionales que se celebran contienen la cláusula arbitral.

En Austria se ha puesto el acento en las pequeñas causas para descongestionar a los tribunales, estableciendo un procedimiento abreviado, utilizándose nuevas tecnologías y dotando a los jueces de relevantes poderes para que ejerzan un rol activo y protagónico.

Pero para los juicios de un monto superior a los diez mil euros no se ha producido mayores cambios procedimentales.(Paul Oberhammer).

Mientras que en el common law se trata de restringir las vías recursivas, en Italia cualquier sentencia es susceptible de recurso, incluso ante el Tribunal Supremo. El ordenamiento procesal italiano contempla diferentes recursos con variadas modalidades de interposición y de substanciación.

El criterio restrictivo en materia recursiva imperante, en el mundo anglosajón se fundamenta según Morello en que la primera instancia es eficaz y actúa con oficio y criterio.

En Italia cualquier ciudadano puede concurrir ante el Tribunal Supremo, lo que genera un verdadero colapso judicial, mientras que en EE.UU. nueve jueces tratan cien cuestiones por año.(Michele Taruffo).

Área americana del norte:

En EE.UU. funcionan doscientas facultades de derecho y están matriculados un millón de abogados. Nadie intenta obtener una magistratura judicial sin que previamente haya tenido experiencia política o tener amigos o aliados políticos. Los jueces más politizados son los jueces federales. El $80 \%$ de los jueces estaduales son designados por elección popular. Los jueces designados políticamente suelen superar intelectualmente a los designados técnicamente. 
Conforme a la tradición inglesa vigente en la totalidad de los estados americanos, con excepción de Lousiana colonizada por Francia, los procedimientos civiles revisten las siguientes características:

- Iniciativa de las partes,

- Facultad de los jueces,

- Mandato judicial,

- Estructura de la vista de causa,

- Cada parte sufraga sus propias costas, los abogados trabajan a resultado.

- Las sentencias dictadas en un Estado pueden ser ejecutadas en otro, salvo violación de normas de orden público o principio de derecho procesal.(Paul D. Carrington).

- Philip Shuchman afirmó que los procedimientos abreviados en EE.UU. constituyen una manera de adoptar medidas urgentes y determinar previamente la necesidad o no de juicio sin producción de medida probatoria. Si se deniega el procedimiento abreviado, resolución que es irrecurrible, continúa el juicio.-

En Canadá se propugnó aumentar los procedimientos abreviados a fin de disminuir costos y reducir los litigios.-

\section{III}

En el ámbito del Coloquio internacional de referencia se llevó a cabo una mesa redonda presidida por el Prof. Konstatinos Kerameus (Atenas), que abordó el tema «Armonización o globalización del procedimiento civil» y a continuación se indicarán los conceptos más sobresalientes de los distintos expositores.

A partir de la aparición de la globalización y el funcionamiento de mercados integrados se impone la necesidad de uniformar las normas procesales vigentes en los diferentes países y de encarar una armonización entre el derecho sustancial y el derecho procesal.

Se afirmó que los factores que obstaculizan la armonización y unificación de las normas procesales radican en las diferentes culturas locales y nacionales. 
En tal sentido, se mencionó el caso de Suiza donde rigen veintisiete códigos de procedimientos, un código civil y una ley uniforme de quiebra. Otro caso que merece señalarse es el que luego de la unificación de las Alemanias no se ha hecho nada para unificar las normas procesales y que actualmente en dicho país, rige un código de procedimientos federal y veintiséis códigos estaduales.

El Tribunal de la Comunidad Europea ha generado una sólida corriente jurisprudencial tendiente a la aproximación de las normas procesales y en los diferentes tratados celebrados, se ha otorgado al Consejo facultades para dictar normas procesales comunes.

A fin de continuar con esta tendencia a la uniformidad y armonización que impulsa la Comunidad Europea, Giuseppe Tarzia reclamó una serie de medidas, tales como un título ejecutivo común para Europa, garantizar el intercambio de la información, dictar normas tendientes a la incautación de depósitos bancarios y viabilizar el exequatur a través de un procedimiento sumarísimo; la tendencia es llegar a la supresión del exequatur.

Sostuvo el catedrático de Milano que el Tratado de Amsterdam ha mejorado el procedimiento en materia de notificaciones y contiene normas comunes en orden a la competencia, concluyendo que toda unificación es ilusoria si no existe un tribunal que garantice la interpretación y aplicación de las normas legales dictadas.

Koen Lenaerts Juez del Tribunal de la Comunidad Europea, señaló las siguientes características del Derecho comunitario europeo:

- Existe primacía sobre los ordenamientos locales.

- Contiene normas procesales.

- No se adopta el sistema dual vigente en los EE.UU., pues no existe federalidad.

- Los tribunales nacionales aplican el derecho comunitario.

- Los tribunales nacionales solicitan consulta al Tribunal de Justicia europeo acerca de la interpretación de una norma de derecho comunitario (cuestión prejudicial); la respuesta es vinculante, no es cosa juzgada es cosa interpretada. Ello ha generado toda una jurisprudencia en materia de interpretación de normas comunitarias.

- Los estados tienen total libertad e independencia para organizar la aplicación del derecho comunitario, la única condición impuesta es que sea lo más eficaz posible reflejada en dos aspectos: 1) debe mediar 
equivalencia, es decir, aplicación idéntica de derecho comunitario y derecho nacional, con prevalencia del primero; y, 2) debe existir eficacia cabal o total eficacia (criterio de razonabilidad).

¿Puede un tribunal nacional aplicar de oficio el derecho comunitario? La respuesta afirmativa sería una consecuencia de la aplicación del principio iura novit curia. Al respecto $\mathrm{K}$. Lenaerts afirmó que la jurisprudencia no es uniforme.

El funcionamiento actual del Tribunal europeo, fue analizado críticamente por Mial Fennelly, abogada general del alto tribunal, quien afirmó enfáticamente que padece de innumerables dificultades atribuibles a:

- El aumento de la litigiosidad provenientes de las acciones directas y de los recursos de apelación.

- La hiperinflación legislativa, se han multiplicado las normas dictadas en la última década, señalando como dato comparativo que en EE.UU. en doscientos años, sólo hubo veintitrés enmiendas constitucionales.

- La mundialización jurídica.

- El incremento de costos y personal, así como exceso de dilación provocado, pues debe trabajarse en once idiomas.

A fin de percibir la magnitud del trabajo que aqueja al Tribunal Supremo europeo, destacó M. Fennelly que en EE.UU. la Corte Suprema recibe ocho mil causas por año y sólo trata cien.

Linda S. Mullenix aludió a "La armonización de normas procesales en EE.UU.» y aseveró que ha sido y es difícil lograr la unificación de normas procesales en EE.UU., ya que actualmente la justicia federal está dividida en noventicuatro distritos, a los que debe adicionarse doce circuitos regionales.

$\mathrm{Al}$ respecto, Paul D. Carrigton acotó que la mayor parte de las contiendas judiciales, el $95 \%$ se radica en los tribunales locales.

Hasta 1938 los tribunales federales debían sujetarse a las normas locales, a partir de entonces se dictó un Código uniforme de procedimientos federal que no sólo unificó las normas en la materia, sino que simplificó la tramitación de los procesos y estableció las acciones de equidad a través de juicio por jurados. 
La mayor parte de los Estados han adoptado las normas contenidas en el Código uniforme. Esta normativa, se ha dicho, implica una limitación constitucional de aquéllos.

$\mathrm{Si}$ bien las interpretaciones jurisprudenciales de los tribunales de apelación difieren, existe una tendencia a unificar criterios.

Afirmó la catedrática de Vilanova, en los EE.UU. que existen tres factores que conspiran con la uniformidad de las normas procesales:

- Todo tribunal de distrito tiene sus normas propias diferentes a las que rigen en el ámbito federal; ello encuentra sustento legal en la Ley $\mathrm{N}^{\circ} 83$.

- La interpretación jurisprudencial de los tribunales inferiores.

- La adopción en 1990 de reformas procesales tendientes a obtener un mejoramiento en el funcionamiento de los tribunales.

- La Corte Suprema de Justicia es un tribunal político por lo que no intenta unificar los criterios interpretativos.

A modo de colofón, sostuvo que en teoría, el sistema federal es uniforme, pero en la práctica está balcanizado.

José Carlos Barbosa Moreira disertó sobre «La unificación de normas procesales en Latinoamérica», y afirmó que el continente presenta diversas peculiaridades, a saber: Brasil tiene sus raíces en el derecho lusitano, mientras que en el resto de los países americanos sus ordenamientos se fundan en el derecho español. Brasil tiene modalidades recursivas diferentes al resto de América. Aquél tiene desde 1939 un sólo Código Procesal, mientras que en Argentina existen tantos códigos como provincias, veintitrés códigos provinciales y un código nacional.

El objetivo perseguido por el Instituto Iberoamericano de Derecho Procesal fue elaborar un Código único que se plasmó en el Código Procesal Civil Modelo para Iberoamérica que se identifica con el de Austria con algunas diferencias, como que la audiencia de vista de causa en éste es optativa. El aludido cuerpo legal fue adoptado por Uruguay que lo sancionó en 1988 y posteriormente sus lineamientos fueron volcados en el Código Procesal Civil, Comercial, Laboral, Rural y Minero de la Provincia de Tierra del Fuego (Argentina) que comenzó a regir en 1994. 
La finalidad del Instituto no es sustituir los códigos vigentes sino inspirar a los legisladores para que apliquen reformas tendientes a lograr un mejoramiento del servicio de justicia.

Si bien es cierto que la idea de armonizar y unificar las normas procesales es una utopía, concluyó Barbosa Moreira, ello no nos debe desanimar y debemos agotar todos los esfuerzos tendientes a lograr tamaño objetivo.

En esa inteligencia y con el espíritu señalado por el eximio procesalista carioca, entendemos que en el ámbito del Mercosur todos los esfuerzos de gobernantes, políticos e intelectuales deben tener como objetivo la creación de un Tribunal de Justicia Supranacional, que se constituirá en el pilar de un sistema transparente, sólido y previsible a fin de garantizar la existencia de una comunidad que se funda en el Derecho y contribuir a consolidar la integración regional.

\section{IV}

El tema central «El poder discrecional del juez: límites y control» fue analizado a través de estos tópicos: "Noción y concepto de la discrecionalidad judicial»; «La discrecionalidad en los procedimientos ordinarios"; "La discrecionalidad en los procedimientos especiales" y «El control de la discrecionalidad judicial».

Al presentar el tema en debate el Presidente de la Asociación Internacional de Derecho Procesal, Prof. Marcel Storme (Bélgica) afirmó que la discrecionalidad del juez es a su vez su límite, su control, el sentido de oportunidad. El juez ocupa una posición central en el proceso que se materializa durante la producción de la prueba y la aplicación del derecho material. Los jueces no pueden ser legisladores de las normas, deben «hacer proceder».

Shimon Shetreet (Israel) definió discrecionalidad como el poder escoger entre varias opciones o alternativas lícitas e implica la idea de selección.

La discrecionalidad judicial se manifiesta en tres aspectos: 1) en la determinación de los hechos pertinentes; 2) en la determinación de las normas aplicables; 3) en la aplicación de las normas a los hechos litigiosos. 
En principio, son las partes las que fijan los hechos sin perjuicio de que el juez tenga en cuenta otros hechos no aducidos por las partes que se incorporan producto de la investigación probatoria, siempre con control de aquéllas.

Burkard Hess (Alemania) sostuvo que el concepto de discrecionalidad judicial es inherente a todo sistema jurídico, que existe divergencias de criterios, pero en general, rige una tendencia hacia la amplitud de la misma.

No cabe duda que el concepto "discrecionalidad judicial» es un término impreciso, que implica libertad de elección y de selección, significa la capacidad del juez de estructurar el juicio.

La discrecionalidad judicial forma parte de los deberes y de los poderes inherentes al juez e implica siempre independencia del juez, éste es el intérprete de la ley («la boca del legislador»).

El control de la discrecionalidad es ejercida por las partes a través de la facultad recursiva. Jamás se lleva a cabo en forma absoluta e ilimitada, siempre es en forma guiada, conforme a pautas; los límites son las garantías constitucionales: 1) igualdad de las partes; 2) derecho a ser oído; 3) proceso justo.

Las conclusiones arribadas por el Prof. Hess fueron las siguientes:

1) La discrecionalidad judicial no puede determinarse globalmente; debemos distinguir la discrecionalidad sustancial que está dada en la aplicación de la ley de la procesal que se materiliza en la dirección del proceso.

2) Toda la doctrina moderna tiende a aumentar el activismo judicial, sea en forma de facultad o de deberes de los jueces, el ejercicio de los mismos no debe afectar el juicio.

3) Reconoce siempre la facultad recursiva de las partes. En la medida que se logre afianzar la legalidad de la primera instancia, los recursos se limitarán. Las pautas del contralor son la razonabilidad y el respeto del principio de proporcionalidad.

4) No es ilimitada depende de los objetivos y de las garantías constitucionales, ésta también exige una gestión judicial oportuna y eficaz.

Karen Broeckx (Bélgica) sostuvo que la discrecionalidad judicial está dada por el poder de apreciación de los hechos litigiosos y para emitir una decisión judicial. 
En Holanda no hay poderes sino facultades discrecionales las que se ejercen en la apreciación de los hechos no esgrimidos por las partes pero que surgen de la investigación y forma parte del proceso, debiéndose cumplimentar el principio de bilateralidad o de contradicción a fin de respetar que las partes ejerzan el derecho de ser oído.

Por su parte, Sakari Laukkanen (Escandinava) afirmó que el concepto de discrecionalidad del juez se presenta en aquellas áreas donde existe carencia de normas y por ende, el juez asume el carácter de legislador, mientras que en el campo reglado por normas legales la discrecionalidad judicial no aparece.

El poder discrecional del juez en Iberoamérica fue presentado por Ignacio Diez Picazo (España) quien sostuvo que existen dos tendencias acerca de la discrecionalidad judicial. Para unos es un fenómeno inexistente, pues se la identifica con la facultad de interpretar la ley la que es inherente a la actividad judicial. La discrecionalidad judicial sólo puede ser entendida como mayor libertad en la interpretación de las normas, en los casos en que la misma contiene conceptos amplios e imprecisos, pero no como facultad de opción entre varias soluciones jurídicamente correctas.

Para otros, existe un amplio número de potestades discrecionales de los jueces en la dirección del proceso, mientras que en la apreciación de los hechos y en la decisión de fondo la discrecionalidad debe considerarse un fenómeno residual.

En Brasil el poder discrecional del juez -expuso Ada de Pellegrini- es muy amplio pues suple la actividad de las partes en la búsqueda de la verdad. En el Código de los Derechos del Consumidor se autoriza a invertir la carga de la prueba. La tendencia es hacia un mayor activismo judicial.

Hay discrecionalidad cuando el juez elige entre dos opciones lícitas, en que la ley no impone ninguna de ellas. Siempre debe ser motivada, fundada y puede ser revisada por la alzada.

El control del acto discrecional se hace efectivo a través del criterio de justicia, de la finalidad social de la justicia y el criterio de proporcionalidad o razonabilidad.

Concluyó que el poder discrecional del juez siempre está limitado por las garantías constitucionales, la prohibición de pruebas ilícitas, el principio de igualdad de las partes y el derecho de ser oído. 
Aníbal Quiroga-León (Perú) afirmó que la discrecionalidad judicial está en la dirección del proceso y en la aplicación del derecho y resaltó la importancia de la capacidad intuitiva de los jueces en la administración de justicia.

Avaló su posición invocando los litigios resueltos por el Rey Salomé, el juez Marshall y el de los jueces legos de Perú en su actividad jurisdiccional cotidiana (En Perú hay tres mil jueces legos y mil quinientos jueces letrados), para finalizar recordando al maestro uruguayo Eduardo J. Couture, «El Derecho nunca me impidió hacer justicia».

En China toda la jurisprudencia está basada en la interpretación abierta de la ley fundada en la subjetividad. No hay determinismo, sino una gran flexibilidad. La capacidad psicológica del juez tiene un rol protagónico. A partir de 1993 se ha puesto en práctica una serie de garantías tendientes a evitar la arbitrariedad que genera el subjetivismo de los magistrados.-

El poder discrecional del juez se manifiesta en la libre evaluación de las pruebas y en la libre decisión de los conflictos teniendo en cuenta los intereses de las partes y la ley.(Ji Wiedong).

En EE.UU. hay una tendencia a aumentar el poder discrecional de los jueces, especialmente antes del juicio; a fin de que las partes arriben a una conciliación, prueba de ello las estadísticas muestran que sólo el 2 o el 3\% de los asuntos civiles llegan a juicio en los EE.UU. A ello debe adicionarse una ostensible restricción en la revisión de los casos por la Alzada. (Philip Shuchman, EE.UU.).

John Peysner (Inglaterra) afirmó que en los sistemas de common law lo que se denomina acto discrecional del juez, no es, sino interpretación y aplicación de la norma jurídica.

La capacidad de decisión de los jueces en el derecho anglosajón es amplísimo; no ocurre lo mismo en el derecho continental, pues aquí el juez no crea la ley.

En abril de 1999 se sancionaron en Inglaterra normas de procedimientos civil que otorgan una mayor discrecionalidad judicial. A tenor de esta reforma afirmó Neil Andrews el Tribunal ejerce poderes para:

1) aplazar la vista de causa, suspender la misma, determinar el orden de los temas a tratarse;

2) adoptar medidas sin instancia de parte y dictar resoluciones tendientes a hacer progresar eficazmente la causa; 
3) suprimir puntos de defensa fundado en que carece de fundamentación, abuso de procedimientos, obstaculizar la justicia o por incumplimiento de normas $u$ órdenes procesales.

4) sugerir a las partes la adopción de métodos alternativos de solución de conflictos.

En los Tribunales de Apelación hay una tendencia a no revisar las resoluciones dictadas en uso de la discrecionalidad judicial. Estas reformas han variado el estilo de los jueces y no pocos poseen la suficiente capacidad para ejercer plenamente las atribuciones otorgadas; y por otra parte, las decisiones judiciales en ejercicio de esa mayor discrecionalidad judicial ha tomado por sorpresa a los litigantes acostumbrados a una pasividad conservadora de los jueces ingleses.

John Peysner acotó al respecto, así como se habla normalmente del miedo de los guardametas ante la ejecución de los penales, existe un miedo generalizado de los abogados ante los poderes de los jueces, es el temor a lo desconocido.

El Prof. Andrews señaló los siguientes peligros de la discrecionalidad:

1) Subjetividad: es injusto que dependa del temperamento del juez.

2) Incoherencia: es inadmisible que se apliquen criterios disímiles para casos iguales, pues se deteriora la seguridad jurídica.

3) Verguenza judicial: no puede atentarse contra el criterio de la comunidad.

Por ello, afirmó que la discrecionalidad judicial irrestricta e ilimitada puede configurar «la tiranía judicial».

También destacó las siguientes ventajas de la discrecionalidad judicial:

1) Impide que el tribunal esta limitado a ritos formales.

2) Implica que la ley sea interpretada.

3) Simplifica los procedimientos al reducir la complejidad de las normas.

4) Entraña ejercicio de soberanía.

De las brillantes exposiciones y del debate suscitado entre los concurrentes, podemos extraer las siguientes conclusiones: 
1) En todas las latitudes, países del common law, del derecho continental, Escandinavia, países asiáticos y africanos, como en Iberoamérica, en fin, toda la doctrina procesal moderna está dirigida hacia un preponderante activismo judicial, abandonando el estatismo de los jueces, al otorgarles mayores facultades y deberes.

La única excepción lo constituyen los países de Europa oriental, que por motivaciones políticas, ajenas a la disciplina jurídica, ante el fracaso del sistema socialista y por el péndulo ideológico han girado hacia una concepción privatística del proceso. No obstante ello, en dichos países comienza a afianzarse una corriente doctrinaria tendiente a otorgar a los jueces facultades para que investiguen y verifiquen la verdad material.

2) Es conciencia casi unánime que en un Estado moderno es del interés público hacer justicia y el único medio éticamente aceptable para ese objetivo es el descubrimiento de la verdad y para el cumplimiento de ese cometido necesitamos contar con jueces que asuman un rol activo en el procedimiento civil con deberes y facultades que le permitan dictar una sentencia justa. Ello implica ejercicio de una soberanía y torna al juez verdaderamente independiente.

3) El poder discrecional del juez es amplio, pero jamás es absoluto. El ejercicio abusivo de la discrecionalidad jurídica lleva al subjetivismo aumentando la imprevisión e inseguridad jurídica. Los límites están en las garantías constitucionales y en los principios fundamentales del proceso: igualdad de las partes, contradicción o bilateralidad y congruencia.

4) A mayor poder de los jueces, un incremento de la responsabilidad de los mismos y un aumento de las facultades de los abogados, ya que la participación activa de éstos equilibrará los poderes y deberes de los jueces y constituirá la garantía más idónea para impedir un ejercicio arbitrario e ilimitado de aquéllos.

5) Si bien la discrecionalidad judicial es una noción abstracta, la misma compete y es ejercida por seres humanos, los jueces, de ahí la importancia que tiene la formación, selección y elección de los magistrados. la discrecionalidad judicial está íntimamente vinculada a la calidad de los jueces, por ende el imperativo es la selección de los mejores. 